\title{
Application of Thermographic Measurements for the Determination of the Impact of Selected Cutting Parameters on the Temperature in the Workpiece During Milling Process
}

\author{
Piotr Zgórniak* - Wojciech Stachurski - Dariusz Ostrowski \\ Lodz University of Technology, Institute of Machine Tools and Production Engineering, Poland
}

\begin{abstract}
In this paper, the impact of selected cutting parameters (both cutting and feed speed) on the temperature generated in the workpiece being machined during milling is assessed. The investigations were carried out by milling of 41Cr4 alloy steel using disc cutter mill with F40M sintered carbide inserts with the anti-wear coating. The investigations were conducted with the dry cutting manner. During the investigations three cutting speeds and three feed speeds were applied, with a constant depth of cut. In the course of the investigations, the temperature in the machining, the zone was recorded using the Flir SC6000HS infrared camera. As a result of the measurements, the mean temperature in the defined measurement zone was determined, and, based on that, a procedure for the determination of the $t_{W \text {-max }}$ maximum temperature in the workpiece being machined has been proposed. Finally, on the basis of the obtained results, it has been found that the increase in cutting speed leads to the increase in the $t_{W-\max }$ maximum temperature, whereas the increase in feed speed leads to the reduction of that temperature in the workpiece being machined.
\end{abstract}

Keywords: machining, IR measurements, workpiece temperature

Highlights

- Application of thermography measurements for the determination of the temperature produced in the workpiece being machined.

- $\quad$ Description of the methodology of the determination of the $t W$-max maximum temperature in the workpiece being machined.

- Determination of the impact of both cutting and feed speeds on the tW-max maximum temperature, in the workpiece being machined.

\section{O INTRODUCTION}

It is well known that the temperature distribution in the cutting zone is highly uneven which causes this zone to be characterized by the presence of a complex temperature field. Because of that, in the literature, e.g. [1], the term of the $t$ cutting temperature is introduced, i.e. the mean temperature on the contact of the cutting edge with chip and the machined surface. In most cases as the cutting temperature the mean temperature in the zone of the contact of the chip with the rake face of the cutting tool is assumed. That temperature is the result of the summary effect of the heat generated due to the plastic strain in the shear zone and the friction of the chip against the rake face of the tool.

Because of the above, many researchers are involved in the determination of the $t$ temperature and analysis of its adverse impact on the cutting edge of the cutting tool. This impact is mainly seen with the reduction of machinability resulting from the reduction of the hardness and durability of the cutting edge [1] to [3].

The temperature distribution in the cutting zone also includes the workpiece being machined. The $t_{W}$ temperature occurring there is the combined effect of the heat generated due to the friction of the flank face of the tool against the machined surface, and the plastic strains preceding the shear of workpiece material and penetrating the surface layer of the workpiece. The adverse effect of temperature in the workpiece being machined may result in the occurrence and increase of adverse internal stresses in the surface layer, or changes in linear dimensions occurring during cooling down, and by this causing errors in the quality of final products [2] and [4]. It should be noted here that the maximum values of the $t_{W-\max }$ temperature occurring in the workpiece being machined are normally much lower than those in chips and the tool [4].

The main factor affecting the temperature value and its distribution in the tool zone, the workpiece being machined and the chip are: the properties of the material being machined and that of the tool, cutting parameters, the cutting edge stereometry and the type and way of cooling down and finally the type of machining operation [5]. As has already been mentioned, most researchers concentrate on the analysis of the cutting edge temperature. In many publications, e.g. [1], the order of the importance of 
the impact of cutting parameters on the $t$ temperature value is described. The strongest impact comes from the $v_{c}$, cutting speed, whereas the impact of the $f$ feed is definitely lower. The impact of the $a_{p}$ cutting depth on the $t$ temperature can normally be neglected. In the study [6], the impact of cutting parameters on cutting temperature was described via the experimental relationship:

$$
t=C_{t} \cdot f^{y_{t}} \cdot v_{c}^{z_{t}}
$$

where $C_{t}, y_{t}$, and $z_{t}$ are constants determined experimentally. For example, for turning low-carbon steel with tool made of sintered carbides the following was obtained:

$$
t=410 \cdot f^{0.13} \cdot v_{c}^{0.23}
$$

and the results are presented in Fig. 1.

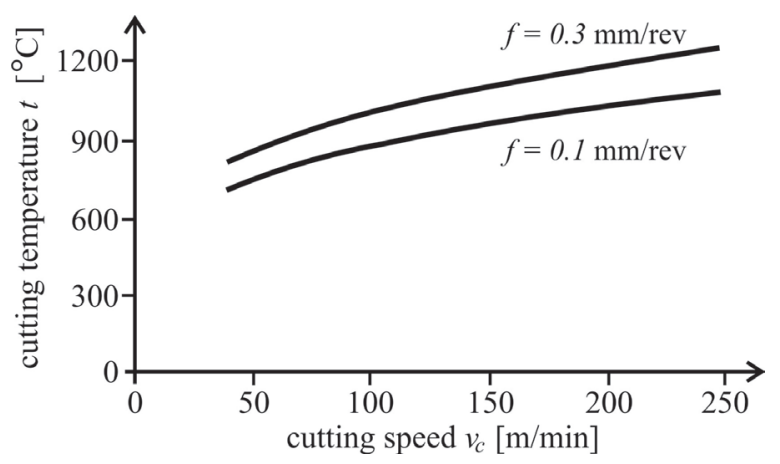

Fig. 1. The impact of cutting speed and feed on the temperature of the cutting blade made of sintered carbides

The comparison of the exponents in the (2) confirms the impact of cutting parameters described above on cutting temperature: the higher impact comes from cutting speed, and the lower one from the feed. As can be seen in Fig. 1, increases in both cutting speed and feed leads to the increase in the temperature of the cutting edge.

The impact of cutting parameters on the temperature of the workpiece being machined is also described in the literature. However, it concerns selected machining conditions and a narrow group of materials being machined. Le Coz and Dudziński [7] carried out investigations concerning the impact of cutting speed on the temperature of the workpiece being machined during the milling of Inconel 718 alloy without the use of any cutting fluid. The investigations were carried out with constant feed and cutting depth. On the basis of those investigations, it was found that similarly as in the case of the temperature of the cutting edge, temperature also increases along with the increase in cutting speed. In another study, O'Sullivan and Cotterell [8] determined the impact of cutting parameters on the temperature of the workpiece during the machining of aluminium alloy. Also, in this case, a similar nature of the temperature changes of the workpiece was observed due to changes in cutting speed. In the case of changes in feed, the matter looked differently. With the increase in feed, the temperature was dropping.

Another important issue that results from the review of the available literature is the influence of many factors, such as cutting conditions, the type of machining process employed to manufacture the part, etc. on the temperatures registered in the cutting zone, particularly within the workpiece. The biggest differences in the temperature values, obtained during the cutting process, result from the type of work performed by the cutting edge. In the case of continuous cutting processes, such as turning or orthogonal cutting, temperatures are much higher than in the case of intermittent cutting once that occurs in the milling process. For example, in [9], Inconel 718 and Ti-6Al-6V-2Sn was machined. Depending on cutting conditions, temperatures obtained in the cutting zone during turning operations ranged from $600{ }^{\circ} \mathrm{C}$ to $1050{ }^{\circ} \mathrm{C}$. In the case of intermittent cutting, temperatures measured on the rake face of the tool varied from $350{ }^{\circ} \mathrm{C}$ to $800{ }^{\circ} \mathrm{C}$. Referring to the results for the orthogonal cutting presented by Artozoul et al. [10], tool temperatures measured with an IR camera ranged from $335{ }^{\circ} \mathrm{C}$ to $670{ }^{\circ} \mathrm{C}$. For comparison, Jiang et al. measured workpiece temperature (1045 steel) by thermocouples during the milling process [11]. Among others results presented in this paper, scientists obtained workpiece temperatures ranging from $35^{\circ} \mathrm{C}$ to $70{ }^{\circ} \mathrm{C}$ for the cutting speeds from $500 \mathrm{~m} / \mathrm{min}$ to $3000 \mathrm{~m} / \mathrm{min}$.

Such a disparity in the obtained temperature values is connected with the nature of the intermittent cutting process in which variable times of heating and cooling appear in the cutting zone. During milling, the ratio of cutting time to time of brake in cutting has a very significant effect on the heat balance in the cutting zone, and thus the value of recorded temperatures. The value of this ratio is primarily determined by the number of cutting teeth, the diameter of the tool or even the dimensions of the samples used in the tests. All this makes it very difficult to compare results achieved in other scientific centres even if was conducted under comparable conditions.

For the determination of cutting temperature analytical, numerical, and experimental methods are used [3] and [4]. In experimental methods, one very popular way of the monitoring of temperature is 
the thermography method using infrared radiation. However, the application of the thermography is not easy in practice [8]. Due to the high sensitivity of this method and the influence of environmental factors on the accuracy of the determination of temperature by means of an IR camera, the interpretation of thermographs requires extensive knowledge and experience in many fields [3] and [12]. Nevertheless, according to the opinions of authors [4], this method illustrates very well the maximum temperatures occurring in the workpiece during the cutting process.

Despite the fact that infrared measurements are considered particularly useful when the tool is rotating, the factors affecting the value of the recorded temperature must be mentioned. One of them is the phenomenon of changes in the emissivity of objects with changes of temperature into the cutting zone. One of the most common ways to eliminate this negative phenomenon is the use of the mean emissivity coefficient for objects made from the same construction materials and equal surface properties. In addition, for the proper determination of the temperature in different areas of the cutting zone often it is necessary to perform many tests and trials to obtain comparable values of temperatures for each component from recorded scene such as the tool, chips, workpiece, surrounding area, etc.

Another way to eliminate the phenomenon of changing emissivity is to apply constant measurement conditions, giving the possibility to use the results of the comparative analysis.

Due to the above drawbacks, many researchers performed analysis of thermal phenomena using the finite element method [13]. The advantage of this solution is undoubtedly the ability to make rapid changes in input variables, regarding the conditions and treatment of its course, in a wider range than is possible in experimental studies. It is thus less expensive, sometimes faster and simpler to implement. However, it should be kept in mind that the temperature values and temperature distributions generated by computer programs do not correspond to strictly experimental results. In addition, lack of knowledge about the algorithms used or assumptions made may result in incorrect conclusions. For obvious reasons, such a comparative analysis of the results obtained from infrared measurement with the results obtained by means of finite element method analysis loses its meaning.

In the Institute of Machine Tools and Production Engineering of the Lodz University of Technology some tests for the measurements of temperature by the thermography method during milling with the use of disc mills were carried out. The investigations were aimed at the development of the methodology of the measurements of the tW temperature in the area of the workpiece being machined along with its determination, and to determine the impact of selected cutting parameters on the tW temperature value.

\section{CONDITIONS OF EXPERIMENTAL INVESTIGATIONS}

In the course of the investigations the samples sized $70 \mathrm{~mm} \times 70 \mathrm{~mm} \times 5 \mathrm{~mm}$ made of $41 \mathrm{Cr} 4$ normalized steel were milled. The milling with the backward method was carried out on a conventional horizontal milling machine.

As the tool, the $335.18-125.17 .40-4 \mathrm{~N}$ disc mill manufactured by SECO was used. It is a three-sided mill clamped on the cutter arbor (An FP type) with 12 cutting edges of the total cutting width $a_{e}=17 \mathrm{~mm}$. Due to the significantly smaller width of the samples (5 mm) 4 edges (no. 1, 4, 7 and 10) arranged on the circumference of the tool every $90^{\circ}$ were used. The way of the setting up of the mill in relation to the material being machined is illustrated in Fig. 2. The LNKT060504PPN-E05 cutting inserts made of F40M sintered carbides from the P40 application area with anti-wear (Ti, Al)N/TiN multilayer coating were used. F40M is the PVD-coated grade for the fine to medium rough milling. The corner radius of the insert was $r_{\varepsilon}=0.4 \mathrm{~mm}$, and the tool rake angle $\gamma=15^{\circ}$ [14].

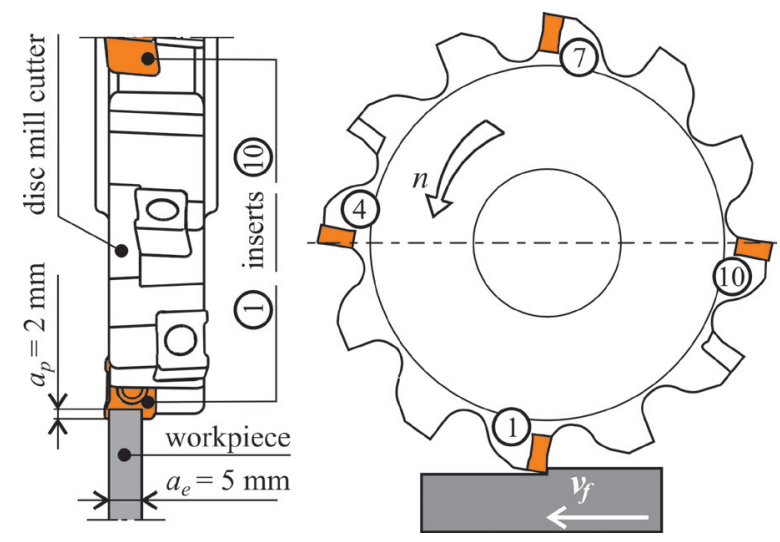

Fig. 2. The view of the cutting zone

Machining was carried out without the use of any cutting fluids (dry machining). Cutting parameters were selected on the basis of the manufacturer's data [15] and the workshop practice. The parameters are presented in Table 1.

The investigation included nine cutting tests. For three cutting speed values, three feed speed levels have been selected. All tests have been done with constant 
depth of cut $a_{p}=2 \mathrm{~mm}$. Each test has been recorded by scientific infrared camera Flir SC6000HS.

Table 1. Cutting parameters

\begin{tabular}{cccc}
\hline Test No & $\begin{array}{c}\text { Feed speed } v_{f} \\
{[\mathrm{~mm} / \mathrm{min}]}\end{array}$ & $\begin{array}{c}\text { Cutting speed } v_{c} \\
{[\mathrm{~m} / \mathrm{min}]}\end{array}$ & $\begin{array}{c}\text { Depth of cut } a_{p} \\
{[\mathrm{~mm}]}\end{array}$ \\
\hline 1 & 42 & & \\
\cline { 1 - 2 } 2 & 52 & 55 & \\
\hline 3 & 69 & & \multirow{2}{*}{2} \\
\hline 4 & 42 & & \\
\hline 5 & 52 & 69 & \\
\hline 6 & 69 & & \\
\hline 7 & 42 & & \\
\hline 8 & 52 & & \\
\hline 9 & 69 & &
\end{tabular}

\section{THE METHODOLOGY OF THERMOGRAPHIC MEASUREMENTS}

During the measurements, thermal photos were recorded with the use of the dynamic expansion of the measurement range of the Flir SC6000HS infrared camera [16] and [17]. To this end, three temperature sub-ranges were used. This enabled assessing the produced temperature in the range of $360{ }^{\circ} \mathrm{C}$, wider than the standard one which is about $120{ }^{\circ} \mathrm{C}$. The milling process was recorded at the maximum possible recording level using 6000 frames being recorded with the ultimate frequency up to $100 \mathrm{~Hz}$. This limitation was caused by the quantity of data being recorded in the RAM memory of the available computer and the possibilities of the recording of infrared thermographic sequences on the hard disk of this computer.

The photos were taken with the resolution of $128 \times 160$ pixels. It means that each thermal frame consists of 128 rows and 160 columns. Because the value of the temperature being recorded is affected by many factors, including the change of the thermal emissivity of the workpiece being machined as temperature increases, in the investigations described here, the average emissivity coefficient $\varepsilon=0.14$ was assumed. The value of this coefficient was obtained based on the emissivity table [17]. This assumption has caused that the ambient temperature being recorded in cutting tests was taking the value of about $45^{\circ} \mathrm{C}$. In fact, the ambient temperature was lower, but the assumption of the thermal emissivity $(\varepsilon=0.92)$ corresponding to that temperature would cause the temperatures being recorded concerning the material being machined to be understated.
For the support of the infrared camera, the IR Control software was used, the graphical interface of which is shown in Fig. 3. The program enables to record the sequences of thermal photos and then, based on the photos, to determine the tmean mean temperature in the AOI0 area which corresponds to the whole thermal frame. Mean temperatures were calculated for the whole sequence. The example of first stage results is presented in Fig. 4. In the second stage authors investigated only the areas that correspond to the workpiece location. Because in each frame the position of the workpiece was different, and the workpiece was moving, only maximum temperatures from rows that correspond to the location of the workpiece were taken into consideration. The maximum temperature was found for a selected frame where the mean maximum temperature was observed and cutting process took place. The next step considered the determination of maximum temperature for the columns where the maximum temperature appeared in the location of the workpiece. The example of the results of maximum temperature in selected frame 3673 is presented in Fig. 6. Here, you can observe greater temperatures concerning chips and lower workpiece temperatures (columns from 1 to 108).

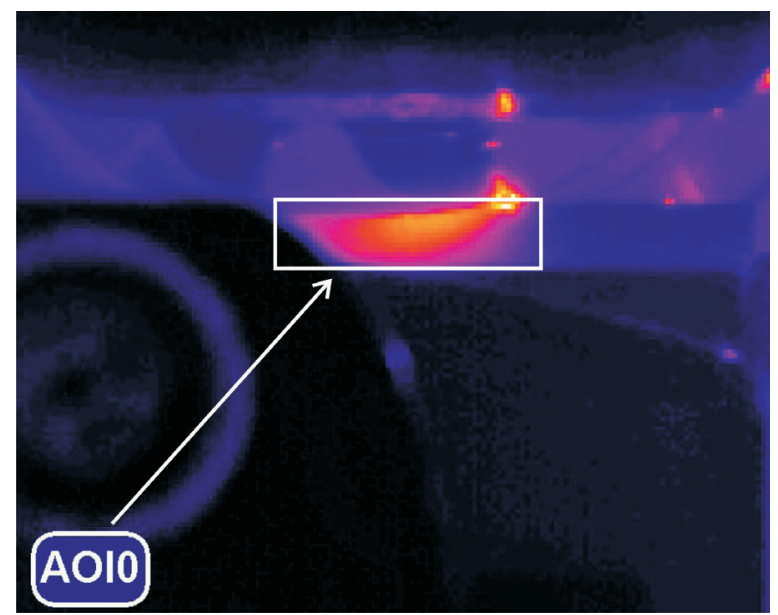

Fig. 3. Graphical interface of the IR Control software

The process of the determination of the temperatures occurring during milling and their assessment were conducted in two stages.

In the first stage, a sequence of thermal photos was recorded (6000 frames), and 9 such sequences were recorded in accordance with the cutting parameters listed in Table 1 (three cutting speeds for three feed values). Next, for each sequence, the program was automatically determining the $t_{\text {mean }}$ mean temperature 
value from the AOI0 area, thus enabling drawing up a chart of the course of its changes during machining.

However, the limitation in the precise definition of the analysed area should be taken into consideration so that it covers the zone of the workpiece being machined. Because of that, the determination of the $t_{\text {mean }}$ temperature is burdened with serious error since the mean temperature value is determined from the area where the temperature of the workpiece being machined, the tool and chips and the environment are recorded. In addition, the milling process is characterized by the lack of permanent contact of the cutting edge with the workpiece being machined and the excess material removed by the cutting edge is uneven. All this leads to the fact that the chart of the course of the changes of the temperature being measured is not stabilized, and the mean temperature value may differ significantly from the maximum temperatures. Fig. 4 illustrates the inconsistencies described above. The charts were made up for three $v_{c}$ cutting speeds at the constant feed speed $v_{f}=42 \mathrm{~mm} / \mathrm{min}$ and they are limited to the time of 30 seconds from the start of machining. When analysing the obtained courses, some local increases in temperature can be noted. This is especially well seen when analysing the chart for the cutting speed $v_{c}=69 \mathrm{~mm} / \mathrm{min}$ in the time interval from the $13^{\text {th }}$ up to the $17^{\text {th }}$ second. The disturbances of this type are caused by the presence of the heated up chips the temperature of which increases the mean temperature in the thermal photo frame.

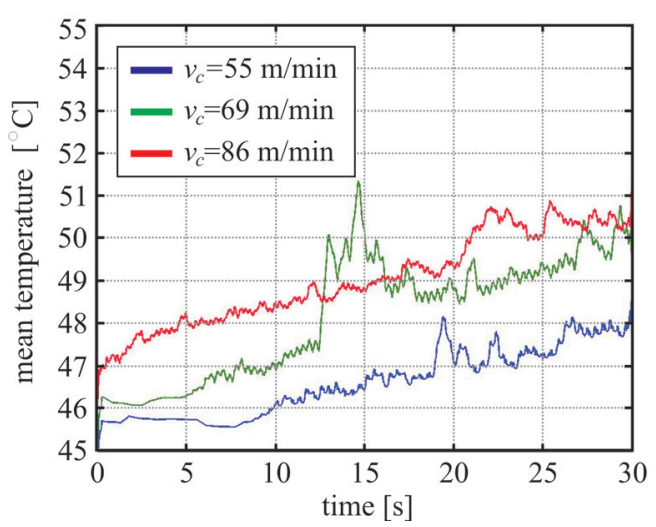

Fig. 4. Mean cutting temperature for the constant feed speed

$$
v_{f}=42 \mathrm{~m} / \mathrm{min}
$$

In the authors' opinion, only the maximum temperature values being recorded in the course of the contact of the cutting edge with the workpiece being machined can be the basis for the determination of cutting temperature and its assessment.
Consequently, the authors developed a procedure for the determination of the maximum temperatures based on the thermographic sequences recorded earlier. That procedure was used in the $2^{\text {nd }}$ stage of the investigations. This stage was limited to the determination of the $t_{W-\max }$ maximum temperature in the workpiece being machined only.

For each single thermal photo sequence, that procedure was starting from the selection of the thermal image in which the cutting with one of four cutting edges was observed. This was because each cutting edge was removing the different amount of the excess material because of the uneven protrusion of cutting inserts from the mill body, and the runout of the cutter arbor. During the initial analyses of the thermographs, it was found that those factors significantly affect the values of the generated temperatures. Then, from such selected frames, those corresponding to the period after the thermal machining conditions had been stabilized were taken. In practice, they were the frames recorded from the time when half of the milling travel (distance) was reached. The procedure of the determination of the maximum temperature was finishing with the selection of one representative frame of thermal photos and, based on that, the determination of the value of the $t_{W-\max }$ temperature. To this end, the selected frame was exported to the *.mat format, and then the distribution of temperature fields was determined in the MatLAB software. As a result of the export, two files come into being. The first one contained the information coming from the calibration file of the infrared camera for specific measurement conditions, whereas the second one included the data concerning the signal values in consecutive matrix pixels of the size equal to the resolution of the thermal frame. Consequently, information the maximum value in the area of the workpiece being machined can be read in the chart of the temperature fields.

For the consecutive sequences of thermal images, the described procedure was repeating itself, whereas every time the same cutting edge was taken into consideration.

\section{RESULTS OF THE INVESTIGATIONS}

In Fig. 5, an example of the chart of the distribution of the temperature fields for the single frame (no. 3673) selected from the sequence of thermal photos is presented. The frame was selected using the procedure described in Section 2. The chart was obtained for the cutting speed $v_{c}=86 \mathrm{~m} / \mathrm{min}$ and the feed speed $v_{f}=69 \mathrm{~mm} / \mathrm{min}$. In order to improve the contrast 
between the isothermal lines of the frame being analysed, the range of the colour changes at the display of various temperatures was narrowed to $60{ }^{\circ} \mathrm{C}$. This was done to improve the readability of the chart.

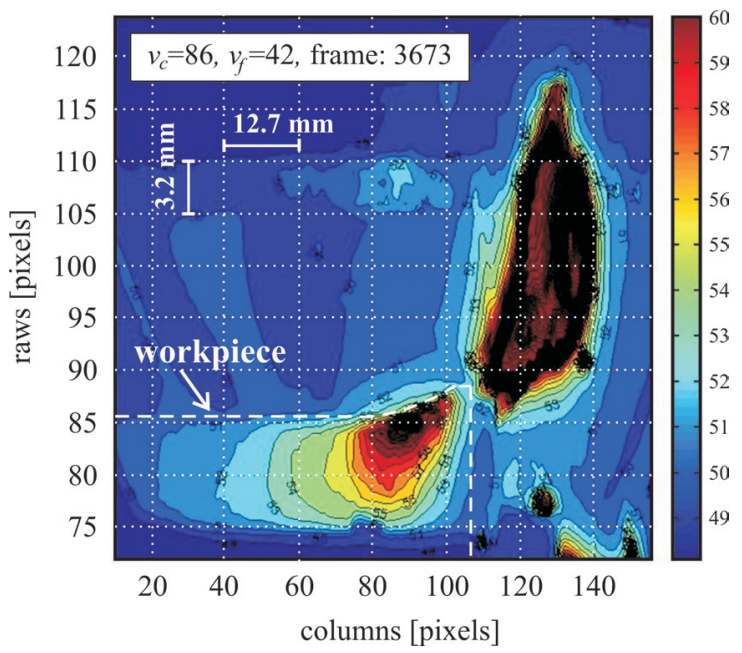

Fig. 5. The distribution of temperature fields for $v_{c}=86 \mathrm{~m} / \mathrm{min}, v_{f}=69 \mathrm{~m} / \mathrm{min}$; frame no. 3673

The process of the determination of the tW-max maximum temperature was starting from the drawing up of the chart of temperature profiles for consecutive columns of the selected frame. Each profile corresponded to one row of the frame. As a result, the chart presented in Fig. 6 was obtained.

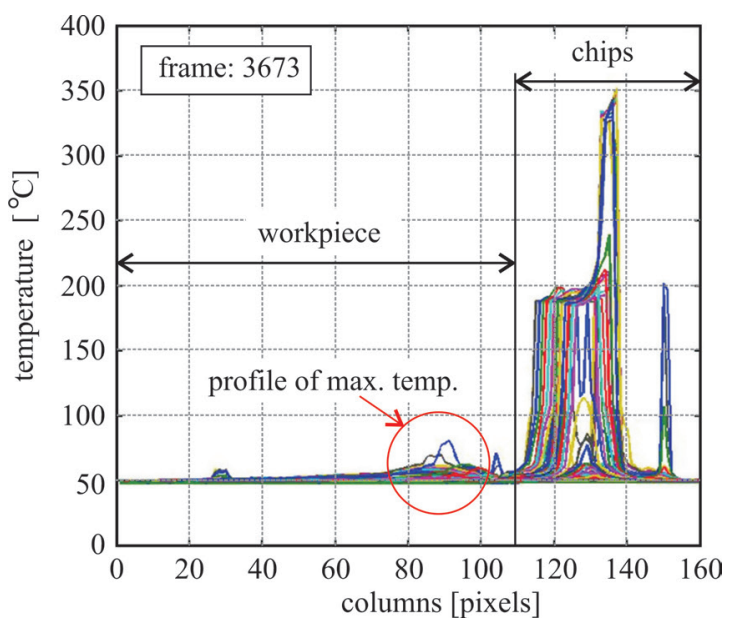

Fig. 6. The temperature profiles for the consecutive columns of the analysed frame no. 3673

After comparing Fig. 6 with Fig. 5 it can be seen that the workpiece is included in the columns from 0 up to 110 . The highest temperature value read in that range was $84.37{ }^{\circ} \mathrm{C}$. It should be observed here that the temperatures being recorded on chips are close to $350{ }^{\circ} \mathrm{C}$ (columns from 110 up to 140 ). The so determined temperature was assumed as the maximum temperature value in the workpiece being machined and compared with the temperatures determined for the frames obtained for other sequences of thermal photos.

In Fig. 7, as an example a chart is presented in which the profiles of the $t_{W-\text { max }}$ maximum temperatures obtained for three $v_{c}$ cutting speeds at constant feed speed $v_{f}=42 \mathrm{~mm} / \mathrm{min}$ are plotted.

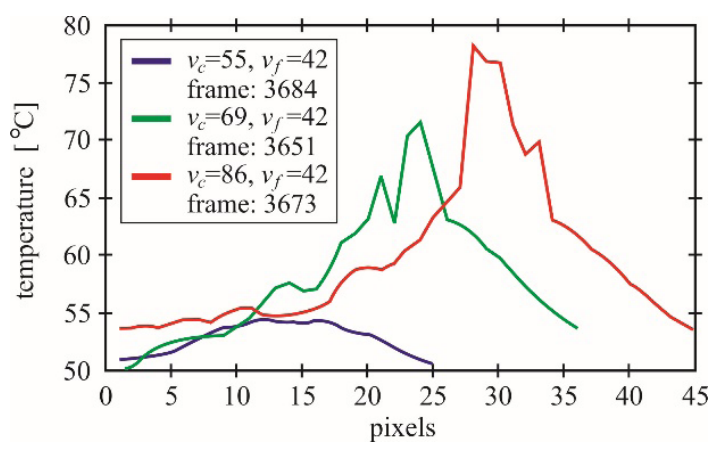

Fig. 7. The profiles of the $t_{W \text {-max }}$ maximum temperatures for different $v c$ cutting speeds at constant feed speed

$$
v_{f}=42 \mathrm{~mm} / \mathrm{min}
$$

Based on the chart presented above it can be seen that the increase in cutting speed at constant feed speed leads to the fact that the $t_{W-\max }$ maximum temperature in the workpiece being machined increases. The values of the measured maximum temperature, and, for comparison, the $t_{\text {mean }}$ mean temperature are tabulated in Table 2. The similar character of the relationship between temperature and cutting speed was observed for the other two $v_{f}$ feed speeds.

Table 2. The maximum and the mean temperature in the workpiece for $v_{f}=42 \mathrm{~mm} / \mathrm{min}$

\begin{tabular}{cccc}
\hline $\begin{array}{c}\text { cutting speed } \\
v_{c}[\mathrm{~m} / \mathrm{min}]\end{array}$ & $\begin{array}{c}\text { feed speed } \\
v_{f}[\mathrm{~mm} / \mathrm{min}]\end{array}$ & $\begin{array}{c}\text { max. temp. } \\
t_{W-\max }\left[{ }^{\circ} \mathrm{C}\right]\end{array}$ & $\begin{array}{c}\text { mean temp. } \\
t_{\text {mean }}\left[{ }^{\circ} \mathrm{C}\right]\end{array}$ \\
\hline 55 & 42 & 54.57 & 50.03 \\
\hline 69 & 42 & 71.58 & 53.59 \\
\hline 86 & 42 & 78.20 & 54.27 \\
\hline
\end{tabular}

Based on the results presented in Table 2, it can be seen that the values $t_{W-\max }$ of the maximum temperatures in the workpiece differ substantially from the values $t_{\text {mean }}$ of the mean temperatures. Only for the cutting speed $v_{c}=55 \mathrm{~m} / \mathrm{min}$ is the difference small, and it amounts to about $9 \%$. For the two other cases, i.e. $v_{c}=69 \mathrm{~m} / \mathrm{min}$ and $v_{c}=86 \mathrm{~m} / \mathrm{min}$ this difference amounts to $33 \%$ and $44 \%$ respectively. 
In Fig. 8, as an example a chart with the $t_{W-\max }$ profiles of the maximum temperatures plotted is presented. The profiles were obtained for three $v_{f}$ feed speeds at constant cutting speed $v_{c}=86 \mathrm{~m} / \mathrm{min}$.

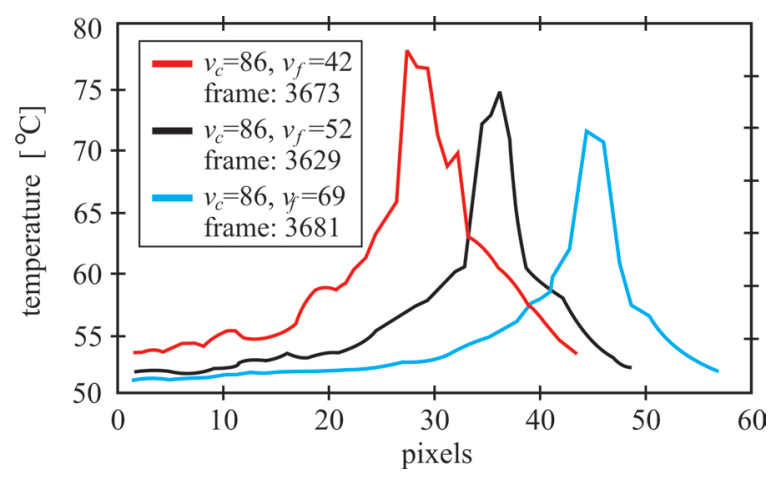

Fig. 8. The profiles of the $t_{W \text {-max }}$ maximum temperatures for different $v f$ feed speeds at constant cutting speed $v_{c}=86 \mathrm{~m} / \mathrm{min}$

On the basis of the chart presented above it can be seen that the increase in feed speed at constant cutting speed leads to the drop of the $t_{W-\max }$ maximum temperature in the workpiece being machined. The values of the maximum measured temperature, and, for comparison, the tmean mean temperature, are tabulated in Table 3. A similar character of the relationship between temperature and feed speed has been observed for the two other vc cutting speeds.

Table 3. The maximum and the mean temperature in the workpiece for $v \mathrm{c}=86 \mathrm{~m} / \mathrm{min}$

\begin{tabular}{cccc}
\hline $\begin{array}{c}\text { cutting speed } \\
v_{c}[\mathrm{~m} / \mathrm{min}]\end{array}$ & $\begin{array}{c}\text { feed speed } \\
v_{f}[\mathrm{~mm} / \mathrm{min}]\end{array}$ & $\begin{array}{c}\text { max. temp. } \\
t_{W-\max }\left[{ }^{\circ} \mathrm{C}\right]\end{array}$ & $\begin{array}{c}\text { mean temp. } \\
t_{\text {mean }}\left[{ }^{\circ} \mathrm{C}\right]\end{array}$ \\
\hline 86 & 42 & 78.20 & 54.27 \\
\hline 86 & 52 & 74.95 & 53.94 \\
\hline 86 & 69 & 71.37 & 53.55 \\
\hline
\end{tabular}

The feature described above is justified in the fact that the increase in feed speed at the same cutting speed leads to the increase in the volume of the material being removed by the tool cutting edge. Thereby the share of the chips in the carrying away of heat from the cutting zone increases.

Based on the results presented in Table 3 it can be seen that the values of the $t_{W-\max }$ maximum temperatures differ substantially from the values of the $t_{\text {mean }}$ mean temperatures. For the speed $v_{f}=42 \mathrm{~mm} / \mathrm{min}$ that difference amounts to $44 \%$, for $v_{f}=52 \mathrm{~mm} / \mathrm{min}$ it is $39 \%$ and for $v_{f}=69 \mathrm{~m} / \mathrm{min}: 33 \%$.

However, results obtained by authors might seem to be too low; it should be taken into consideration that differences in comparison to others' works are the result of the methodology adopted. Kitigawa et al. [9] investigated temperature during the highspeed machining of Inconel 718 and Ti-6Al-6V-2Sn hard to cut materials. It is not surprising that in this case, authors obtained a higher temperature value $\left(350{ }^{\circ} \mathrm{C}\right)$. Temperatures have been determined by a thermocouple mounted into single point cutting tool. In the paper Artozoul et al. [10], investigated infrared measurements, but temperatures were investigated using an orthogonal cutting model, and the temperature was determined by a cutting tool, not in the workpiece. In this case, intermittent cutting phenomena was not taken into consideration, so the values were higher than author's results. Moreover, cutting parameters used by Artozoul et al. [10], are higher $\left(v_{c}=100 \mathrm{~m} / \mathrm{min}\right.$ and $v_{c}=250 \mathrm{~m} / \mathrm{min}$ ) than values applied in our tests, so it is not surprising that the values obtained in these studies are higher. Referring to the work of Jiang et al. [11], temperatures were measured by a thermocouple mounted into the workpiece, and an intermittent cutting effect appeared during the cutting test. Here, the results of the workpiece temperature obtained by the authors are close to ours, despite the fact that the cutting velocity applied was higher and ranges from $500 \mathrm{~m} / \mathrm{min}$ to $3000 \mathrm{~m} / \mathrm{min}$. In this case, the measured temperatures obtained ranges from $30^{\circ} \mathrm{C}$ to $70{ }^{\circ} \mathrm{C}$.

\section{CONCLUSIONS}

On the basis of the results presented above, the following conclusion can be formulated:

1. The use of an infrared camera enables carrying out the analyses of the impact of cutting parameters on the temperature generated in the workpiece being machined.

2. For the investigations of cutting processes, the maximum temperature should be used. It is more reliable than the mean temperature.

3. The application of the method proposed by the authors enables the precise temperature analyses for the individual cutting edges. This is so because the limitation in the temperature recording time to the period in the conditions stabilized by the elimination of the heating up phase (start of cutting) and the retraction of the tool from the workpiece phase makes it possible to increase the frequency of recording thermal images. On the basis of the current investigations [12], it was found that the phases of entering and retracting the tool to/from the workpiece being machined cause significant discrepancies in the final results being obtained. 
4. The increase in the cutting speed at constant feed speed in the investigated range causes the increase in the $t_{W-\max }$ maximum temperature in the workpiece being machined.

5. The increase in the feed speed at constant cutting speed in the investigated range causes the $t_{\text {mean }}$ mean temperature to drop in the workpiece being machined. This is because the share of chips in carrying away the heat from the cutting zone increases.

6. The level of temperature values presented in the paper, concerning workpiece temperature distribution, is close to the results presented in other available literature, e.g. [11]

7. Further investigations should take into account the variability of the thermal emissivity coefficient as the temperature in various areas of the cutting zone increases. It is planned to take into account the changes of the emissivity coefficient of the workpiece being machined, the tool, and the environment.

8. Despite the fact that thermocouple measurements have many disadvantages, e.g. difficulties in precise location in the workpiece, disruption of thermal field, measurements only in one or several points into the cutting zone, etc., it might be a good idea to use this measuring method for the validation and calibration of thermographic measurements. This issue will be the subject of future research.

\section{REFERENCES}

[1] Grzesik W. (2008). Advanced Machining Processes of Metalic Materials. Theory, Modeling and Applications, Elseviere Science, Amsterdam.

[2] Grzesik, W., Kruszyński, B. Ruszaj, A. (2010). Surface integrity of machined surfaces. Davim, J.P. (ed.) Surface Integrity in Machining, Springer, London, D0I:10.1007/978-1-84882-8742.

[3] Abukhshim, N.A., Mativenga, P.T., Sheikh, M.A. (2006). Heat generation and temperature prediction in metal cutting: $A$ review and implications for high speed machining. International Journal of Machine Tools and Manufacture, vol. 46, no. 7-8, p. 782-800, D0I:10.1016/j.jimachtools.2005.07.024.

[4] Da Silva, M.B., Wallbank, J. (1999). Cutting temperature: prediction and measurement methods - a review. Journal of
Materials Processing Technology, vol. 88, no. 1-3, p. 195-202, D0I:10.1016/S0924-0136(98)00395-1.

[5] Byrne G., Dornfeld, D., Denkena, B. (2003). Advancing cutting technology. CIRP Annals - Manufacturing Technology, vol. 52, no. 2, p. 483-507, D0l:10.1016/S0007-8506(07)60200-5.

[6] Jemielniak, K. (2012). Metal Machining. Warsaw University of Technology Publishing House, Warsaw. (in Polish)

[7] Le Coz, G., Dudzinski, D. (2014). Temperature variation in the workpiece and in the cutting tool when dry milling Inconel 718. The International Journal of Advanced Manufacturing Technology, vol. 74, no. 5, p. 1133-1139, Dol:10.1007/ s00170-014-6006-1.

[8] O'Sullivan, D., Cotterell, M. (2002). Workpiece temperature measurement in machining. Proceedings of the Institution of Mechanical Engineers, Part B: Journal of Engineering Manufacture, vol. 216, no. 1, p. 135-139, DOI:10.1243/0954405021519645.

[9] Kitigawa, T., Kubo, A., Maekawa, K. (1997). Temperature and wear of cutting tools in high-speed machining of Inconel 718 and Ti-6Al-6V-2Sn. Wear, vol. 202, no. 2, p. 142-148, DOI:10.1016/S0043-1648(96)07255-9.

[10] Artozoul, J., Lescalier, Ch., Bomont, O., Dudzinski, D. (2014). Extended infrared thermography applied to orthogonal cutting: Mechanical and thermal aspects. Applied Thermal Engineering, vol. 64, no. 1-2, p. 441-452, D0l:10.1016/j. applthermaleng.2013.12.057.

[11] Jiang, F., Liu, Z., Wan, Y., Shi, Z. (2013). Analytical modeling and experimental investigation of tool and workpiece temperatures for interrupted cutting 1045 steel by inverse heat conduction method. Journal of Materials Processing Technology, vol. 213, no. 6, p. 887-894, D0l:10.1016/j.jmatprotec.2013.01.004.

[12] Kuczmaszewski, J., Zagórski, I. (2013). Methodological problems of temperature measurement in the cutting area during milling magnesium alloys. Management and Production Engineering Review, vol. 4, no. 3, p. 26-33, Dol:10.2478/ mper-2013-0025.

[13] Özel, T., Altan, T. (2000). Process simulation using finite element method - prediction of cutting forces, tool stresses and temperatures in high-speed flat end milling. International Journal of Machine Tools and Manufacture, vol. 40, no. 5, , p. 713-738, D0l:10.1016/S0890-6955(99)00080-2.

[14] SECO (2014). 335 Series Disc Milling, from http://www. secotools.com, accessed on 2015-06-17.

[15] SECO (2014). Milling - catalogue and technical guide, from http://www.secotools.com, accessed on 2015-06-17.

[16] Zgórniak, P., Grdulska, A. (2012). Investigation of temperature distribution during milling process of AZ91HP magnesium alloys. Mechanics and Mechanical Engineering, vol. 16, no. 1, p. 33-40.

[17] Bramson, M.A. (1968). Infrared Radiation, A Handbook for Applications. Plenum Press, New York, D0l:10.1007/978-14757-0911-7, Dol:10.1007/978-1-4757-0911-7. 